\title{
Traditional Chinese Medicine Extract from Huaier Increases the Expression of Duffy Antigen Receptor for Chemokines and Reduces the Expression of Its Ligands
}

\author{
Ying Chen (D), ${ }^{1}$ Qianjun Chen, ${ }^{1}$ Fengfeng Xie, ${ }^{1}$ Hui Peng, ${ }^{2}$ Yanlan Wu, ${ }^{1}$ Shaowen Zhong, \\ Zhiyu Wang $\mathbb{D}^{1}{ }^{1}$ Wenxia $\mathrm{Li}^{3}$ and Wanjun Xie ${ }^{1}$
}

${ }^{1}$ Department of Breast Surgery, Guangdong Traditional Chinese Medicine Hospital, Guangzhou, Guangdong 510000, China

${ }^{2}$ Department of Pathology, Guangdong Traditional Chinese Medicine Hospital, Guangzhou, Guangdong 510000, China

${ }^{3}$ Department of Anesthesia, Guangdong Traditional Chinese Medicine Hospital, Guangzhou, Guangdong 510000, China

Correspondence should be addressed to Ying Chen; 15989280535@139.com

Ying Chen and Qianjun Chen contributed equally to this work.

Received 7 January 2018; Revised 10 May 2018; Accepted 12 June 2018; Published 24 July 2018

Academic Editor: Consuelo Amantini

Copyright (c) 2018 Ying Chen et al. This is an open access article distributed under the Creative Commons Attribution License, which permits unrestricted use, distribution, and reproduction in any medium, provided the original work is properly cited.

\begin{abstract}
Aims. The aim of the present study is to investigate whether the aqueous extract from Huaier, a traditional Chinese medicine (TCM), can affect the expression of Duffy antigen receptor for chemokines (DARC) and its ligands. Moreover, we compare the status of DARC in primary and metastatic breast cancer tissues from the same patient. Methods. Immunohistochemistry was used to detect the expression of DARC in primary and metastatic focuses in 30 patients with breast cancer. The effect of Huaier aqueous extract on the expression of DARC and its ligands was investigated by quantitative real-time polymerase chain reaction, Western blotting, and enzyme-linked immunosorbent assay. Results. The expression score of DARC in primary focuses was significantly higher than that in metastatic focuses, while changes of ER, PR, and HER2 receptors were not significantly different between primary and metastatic focuses. Huaier aqueous extract promoted the expression of DARC and reduced the secretion of CC chemokine ligand 2 (CCL-2), CXC chemokine ligand 8 (CXCL-8, IL-8), matrix metalloproteinase 2 (MMP-2), and CXC chemokine ligand 1 (CXCL-1). Conclusion. The present study demonstrates that difference in expression level of DARC between primary and metastatic focuses of breast cancer was significant, while differences in expression of ER, PR, and HER2 between primary and metastatic focuses were not significant. DARC may play a negative role in the metastasis of breast cancer. Traditional Chinese medicine extract from Huaier can increase DARC expression and reduce the expression of its ligands such as CCL-2, IL-8, MMP-2, and CXCL-1.
\end{abstract}

\section{Introduction}

Breast cancer is the most severe malignant tumor in women in China [1]. The major cause of mortality from breast cancer is metastasis to distant organs. However, the 5-year survival rate of patients with metastatic breast cancer is still around $25 \%$, and the median survival period is about $2-3$ years $[2,3]$.

Chemokines are a class of specific small-molecule proteins that play important roles in the recruitment and activation of leukocytes. They have also been highlighted in cancer progression and metastasis, as well as the regulation of host immune responses. There are some special chemokine receptors that are incapable of transmitting their signals through classic $G$ protein-mediated pathways. Therefore, these receptors act as scavengers by efficiently internalizing their cognate chemokine ligands [4].

Duffy antigen receptor for chemokines (DARC) is a typical chemokine decoy receptor that is first discovered in hemophiliacs. It is widely expressed on erythrocytes and vascular endothelial cells. DARC can bind to chemokines that are associated with angiogenesis. Since DARC lacks 7 transmembrane glycoproteins, DARC does not cause cell signal transduction 
or cell metabolism after binding with its ligands [5]. It has been shown that DARC is involved as a negative regulator in the pathogenesis of common cancers, mainly by sequestrating promalignant chemokines. Several studies show that downregulation of DARC indicates poor prognosis of breast cancer, colorectal cancer, prostate cancer, cervical squamous cell cancer, thyroid cancer, and gastric cancer [6-10].

Hormone receptor-positive MCF-7 cells express high levels of DARC, and triple negative MDA-MB-231 cells express low levels of DARC. The biological behaviors of hormone receptor-positive cancers seem to be more gentle than those of triple negative cancers, and the expression level of DARC is associated with the grade of malignancy. When enhancing DARC expression by gene transfection, cell growth and metastasis potential are reduced [10]. If there is one way to enhance DARC expression by an extraneous factor, it can be an important method to reduce breast cancer metastasis.

Traditional Chinese medicine, a rich source of potent anticancer agents, is attracting increasing attention worldwide. Recently, the anticancer activity of Trametes robiniophila Murr. (Huaier) has been widely investigated. Huaier is isolated from the extract of officinal fungi that has been used in traditional Chinese medicine for approximately 1600 years, and proteoglycan has been identified as the effective ingredient [11]. It has been widely used in the treatment of breast cancer, liver cancer, prostate cancer, and gynecological malignant tumors [12-14].

Previous studies show that Huaier aqueous extract can inhibit the proliferation of breast cancer cells by inducing apoptosis, suppress tumor metastasis, induce autophagic cell deaths, disturb DNA repair, and stimulate the ability of T and B lymphocytes $[11,15,16]$. However, the mechanisms are not fully understood yet. Whether Huaier aqueous extract affects the expression of chemokines and DARC has not been investigated. To test our hypothesis, we compare the expression of DARC in primary and metastatic breast cancer. Then, we investigate the effect of Huaier aqueous extract on the expression of DARC and its ligand chemokines.

\section{Materials and Methods}

2.1. Patients. A total of 30 female patients with breast cancer were selected from Guangdong Traditional Chinese Medicine Hospital (Guangzhou, China) for the study. Tumor specimens were all invasive ductal carcinomas, according to the WHO tumor classification. The mean age of patients with primary breast cancer was 50.33 years (ranging from 29 to 69 years). However, average age of these patients when recurrence and metastasis occurred was 52.9 years (ranging from 34 to 71 years). The mean disease-free survival (DFS) time was 2.6 years (ranging from 1 to 9 years). According to the clinicopathological surrogate definitions of subtypes which were adopted by the 13th St. Gallen International Breast Cancer Conference (2013) Expert Panel [17], we divided the patients into 4 groups. In addition, 3 cases were Luminal Alike, 11 cases were Luminal B-like (human epidermal growth factor receptor 2- (HER2-) negative), 5 cases were Luminal B-like (HER2-positive), 3 cases were HER2-positive
TABLE 1: General data of patients with primary tumor.

\begin{tabular}{|c|c|c|}
\hline \multirow{2}{*}{ Age (years) } & $\leq 40$ & 6 \\
\hline & $\geq 40$ & 24 \\
\hline \multirow{2}{*}{ Tumor size } & $\mathrm{T} 1$ & 8 \\
\hline & $\mathrm{T} 2$ & 22 \\
\hline \multirow{4}{*}{ Lymph node metastasis } & N0 & 12 \\
\hline & N1 & 6 \\
\hline & N2 & 7 \\
\hline & N3 & 5 \\
\hline \multirow{3}{*}{ Pathological grade } & 1 & 1 \\
\hline & 2 & 15 \\
\hline & 3 & 14 \\
\hline \multirow{7}{*}{ Clinical stage } & IA & 6 \\
\hline & IB & 0 \\
\hline & IIA & 9 \\
\hline & IIB & 4 \\
\hline & IIIA & 6 \\
\hline & IIIB & 0 \\
\hline & IIIC & 5 \\
\hline \multirow{2}{*}{ ER } & Positive & 19 \\
\hline & Negative & 11 \\
\hline \multirow{2}{*}{ PR } & Positive & 16 \\
\hline & Negative & 14 \\
\hline \multirow{2}{*}{ HER2 } & Positive & 8 \\
\hline & Negative & 22 \\
\hline
\end{tabular}

(nonluminal), and 8 cases were triple negative (ductal). Informed consent was obtained from each patient prior to enrollment in the study. All specimens were obtained following informed consent, and procedures were conducted in accordance with Ethical Standards of the Declaration of Helsinki. Written permission was provided by the hospital and local ethics committee of Guangdong Traditional Chinese Medicine Hospital for the study. The primary tumor characteristics are presented in Table 1.

2.2. Immunohistochemical Staining. Sections were incubated with goat anti-human anti-DARC polyclonal antibody (1:100 dilution; Santa Cruz, CA, USA) at $4^{\circ} \mathrm{C}$ overnight. $\mathrm{ABC}$ peroxidase staining was then employed, according to the manufacturer's instructions (Vector Laboratories, Burlingame, CA, USA). Colorimetric detection was performed with 3,3'-diaminobenzidine (DAB). Positive reactions were defined as those showing brown signals in cell cytoplasm and cytomembrane. For DARC, a staining index (values 0-12) was determined by multiplying the score for staining intensity with the score for positive area. The intensity was scored as follows: 0 , negative; 1 , weak; 2, moderate; and 3, strong. The frequency of positive cells was defined as follows: 0 , less than $5 \% ; 1,5 \%-25 \% ; 2,26 \%-50 \% ; 3,51 \%-75 \%$; and 4 , greater than $75 \%$. The last score was intensity score multiplied by frequency score. For ER, PR, and HER2, the determinations were performed by Pathology Department of Guangdong Traditional Chinese Medicine Hospital. 
TABLE 2: Specific primers of DARC and other relevant molecules.

\begin{tabular}{lc}
\hline H-CCL-2-F & ACAAGCAAACCCAAACTCCG \\
H-CCL-2-R & AAACAGGGTGTCTGGGGAAA \\
H-MMP-2-F & GGAAGTCTGTGTTGTCCAGAGG \\
H-MMP-2-R & CCAAGCGGTCTAAGTCCAGAG \\
H-CXCL1-F & CTGGCTTAGAACAAAGGGGCT \\
H-CXCL1-R & TAAAGGTAGCCCTTGTTTCCCC \\
h-IL-8(CXCL8)-f & GGTGCAGTTTTGCCAAGGAG \\
h-IL-8(CXCL8)-r & TGGGGTGGAAAGGTTTGGAG \\
H-ACTB-F-2 & CATGTACGTTGCTATCCAGGC \\
H-ACTB-R-2 & CTCCTTAATGTCACGCACGAT \\
\hline
\end{tabular}

2.3. Cells. MDA-MB-231 and MCF-7 cell lines were obtained from American Type Culture Collection (ATCC) (Manassas, VA, USA). MDA-MB-231 cells were maintained in L15 medium supplemented with $10 \%$ fetal bovine serum at $37^{\circ} \mathrm{C}$ in sterile culture dishes. MCF-7 cells were cultured in RPMI-1640 medium supplemented with 10\% fetal bovine serum and penicillin-streptomycin (Flow Laboratories, Rockville, MD) at $37^{\circ} \mathrm{C}$. All cell lines were certified to be mycoplasma-free. Then, we treated the cells with $4 \mathrm{mg} / \mathrm{ml}$ or $8 \mathrm{mg} / \mathrm{ml}$ Huaier aqueous extract for $24 \mathrm{~h}$ or $48 \mathrm{~h}$.

2.4. Quantitative Real-Time Polymerase Chain Reaction ( $q R T-P C R)$. Total RNA was isolated with TRIzol reagent following the manufacturer's manual (Thermo Fisher Scientific, Waltham, MA, USA). RNA was treated with DNase. Total RNA $(1 \mu \mathrm{g})$ was converted to cDNA using RevertAid First Strand cDNA Synthesis Kit (Thermo Fisher Scientific, Waltham, MA, USA). Specific primers of DARC and other relevant molecules used in the experiments are shown in Table 2. The amplified products were electrophoresed on a $1.2 \%$ agarose gel and stained with ethidium bromide.

qRT-PCR was performed using fluorescence temperature cycler (Opticon, MJ Research, St. Bruno, Canada) and SYBR Green PCR core reagent kit according to the manufacturer's instructions (Takara, Dalian, China). An initial incubation of $50^{\circ} \mathrm{C}$ for $2 \mathrm{~min}$ was followed by denaturing at $95^{\circ} \mathrm{C}$ for $10 \mathrm{sec}$ and then 40 cycles at $95^{\circ} \mathrm{C}$ for $15 \mathrm{~s}$ and $60^{\circ} \mathrm{C}$ for $1 \mathrm{~min}$. PCR products were detected by bound SYBR Green doublestranded DNA fluorescence, and the comparative threshold cycle $\left(2^{-\Delta \Delta \mathrm{cT}}\right)$ method was used to enable quantification of mRNA of these genes. All samples were tested in triplicate. Target gene expression was compared to the housekeeping gene GAPDH. After PCR, a melting curve was obtained and analyzed.

2.5. Enzyme-Linked Immunosorbent Assay (ELISA). Cells were seeded in six-well plates before being treated with Huaier aqueous extract. After $24 \mathrm{~h}$ of growth, $1.5 \mathrm{ml}$ of medium was collected from each well to evaluate the levels of CC chemokine ligand 2 (CCL-2), CXC chemokine ligand 8 (CXCL-8, IL-8), matrix metalloproteinase 2 (MMP-2), and CXC chemokine ligand 1 (CXCL-1) by ELISA. The supernatants from each time point were collected and analyzed for the protein expression using a commercially available ELISA kit (DuoSet, R\&D Systems Inc., Minneapolis, MN, USA) according to the manufacturer's instructions. The plates were read at $450 \mathrm{~nm}$. Protein concentrations in conditioned media were calculated from a standard curve generated by adding recombinant to specific unconditioned media.

2.6. Western Blotting. Proteins were extracted from cultured cells and then quantitated with the bicinchoninic acid (BCA) assay kit (Pierce, Rockford, IL, USA), using bovine serum albumin as standard. Equal amounts of protein $(50 \mu \mathrm{g})$ from different cells were separated by $10 \%$ SDSPAGE and then incubated with antibodies against target proteins. Target proteins were detected by enhanced chemiluminescence (ECL) kit (Amersham Pharmacia Biotech, Uppsala, Sweden) and exposed to BioMax ML film (Eastman Kodak, Rochester, NY, USA). Images were captured by Alpha Image 950 documentation system (Alpha Innotech, San Leandro, CA, USA).

2.7. Statistical Analysis. Data were expressed as means \pm SD. SPSS software 13.0 version (IBM, Armonk, NY, USA) was used for statistical analysis. Difference in the expression of DARC between primary and metastatic tumors was assessed using Pearson's $\chi^{2}$ test.

\section{Results}

3.1. Expression Level of DARC in Primary Breast Cancer Tissues Is Significantly Higher than That in Metastatic Tissues. Before investigating the expression levels of DARC in primary and metastatic breast cancer tissues, the expressions of HER2, estrogen receptor (ER), and progesterone (PR) were first measured. The expression of HER2 in 3 patients turned from negative in primary tumor tissues to positive in metastatic tumor tissues. ER expression in 9 patients and $\mathrm{PR}$ expression in 7 patients were positive in both primary tumor tissues and metastatic tumor tissues. Total discordance rates of HER2, ER, and PR were 30\%, 23\%, and $10 \%$, respectively, but the expression changes of HER2, ER, and PR were not significantly different between primary and metastatic foci. The expression score of DARC in primary foci was significantly higher than that in metastatic foci $(P<0.05)$ (Figure 1 and Table 3$)$. The result suggests that the expression score of DARC in primary breast cancer tissues is significantly higher than that in metastatic tissues.

3.2. Treatment with Huaier Aqueous Extract Enhances the Expression of DARC in MCF-7 and MDA-MB-231 Cells. To investigate the expression changes of DARC after treatment with Huaier aqueous extract, qRT-PCR and Western blotting were performed on MD-MB-231 and MCF-7 cells. The data showed that mRNA expression levels of DARC after treatment with Huaier aqueous extract ( 4 or $8 \mathrm{mg} / \mathrm{ml}$ ) for 24 or $48 \mathrm{~h}$ were significantly higher than that in control $(P<0.05$; Figure 2), and protein expression levels of DARC after treatment with Huaier aqueous extract ( 4 or $8 \mathrm{mg} / \mathrm{ml}$ ) for $48 \mathrm{~h}$ were significantly higher than those in control $(P<0.05$; Figure 3 ). The results indicate that treatment with Huaier aqueous extract enhances the expression of DARC in MCF7 and MDA-MB-231 cells. 


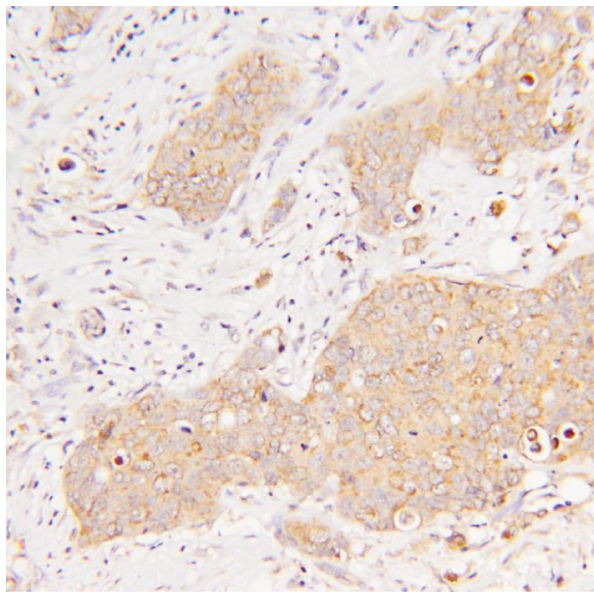

(a)

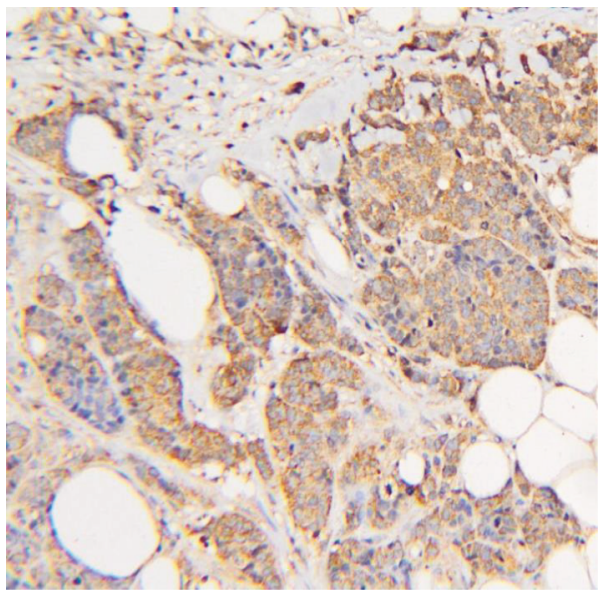

(c)

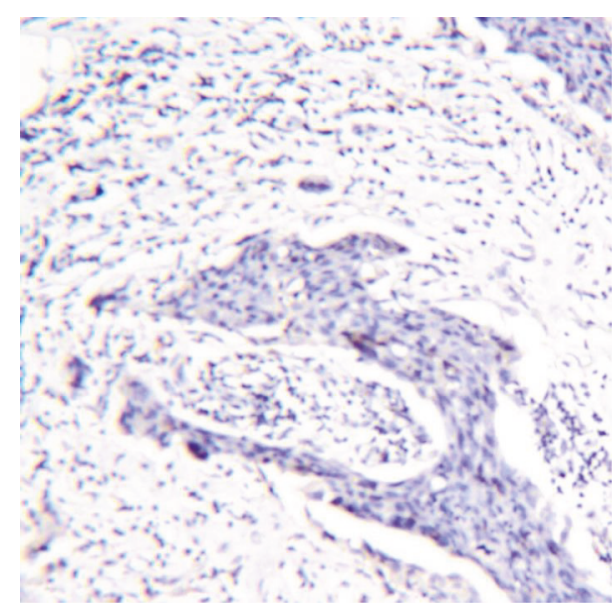

(b)

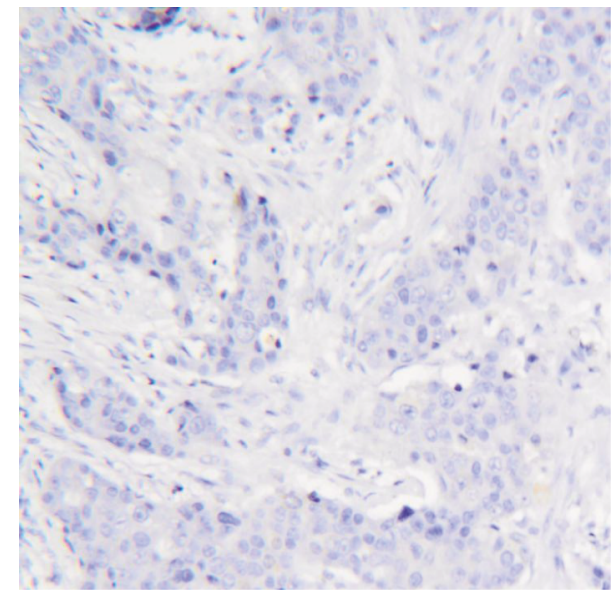

(d)

FIGURE 1: Expression of DARC in human primary and metastatic breast cancer tissue samples with immunohistochemical staining. (a, b) Patient 1: (a) primary tissues $(\times 20$, positive 8 scores) and (b) metastatic tissues $(\times 20$, negative 0 scores). (c, d) Patient 2: (c) primary tissues $(\times 20$, positive 12 scores $)$ and $(\mathrm{d})$ metastatic tissues $(\times 20$, negative 0 scores $)$.

TABle 3: Expression score of DARC in primary and metastatic breast cancer tissues.

\begin{tabular}{lcccc}
\hline & Groups & $N$ & Means & $P$ \\
\hline \multirow{2}{*}{ The score of DARC } & Primary & 30 & 6.7667 & \multirow{2}{*}{0.001} \\
& Metastatic & 30 & 3.1333 & \\
\hline
\end{tabular}

3.3. The mRNA Expression Levels of the Ligands of DARC Are Reduced by Huaier Aqueous Extract, Especially in MCF-7 Cells. To study the effect of Huaier aqueous extract on the ligands of DARC in vitro, qRT-PCR was also employed. The data showed that mRNA expression levels of CXCL-1, IL-8, CCL-2, and MMP-2 in MCF-7 cells after treatment with Huaier aqueous extract $(4 \mathrm{or} 8 \mathrm{mg} / \mathrm{ml})$ for $24 \mathrm{~h}$ were significantly lower than that in control $(P<0.05)$ (Figure 4(a)). However, mRNA levels of CCL-2 but not CXCL-1, IL-8, and MMP-2 were significantly reduced by treatment with Huaier aqueous extract ( 4 or $8 \mathrm{mg} / \mathrm{ml}$ ) in MDA-MB-231 cells $(P<0.05)$ (Figure $4(\mathrm{~b}))$. These results suggest that mRNA expression levels of the ligands of DARC could also be reduced by Huaier aqueous extract, especially in MCF-7 cells.

3.4. Huaier Aqueous Extract Decreases the Secretion of DARC Ligands by MCF-7 and MDA-MB-231 Cells In Vitro. To test the effect of Huaier aqueous extract ( 4 or $8 \mathrm{mg} / \mathrm{ml}$ ) for $48 \mathrm{~h}$ on the secretion of DARC ligands in vitro, ELISA was carried out. The data showed that treatment with Huaier aqueous extract significantly reduced the secretion of DARC ligands compared with the control in both MCF-7 and MDA-MB231 cells $(P<0.05)$ (Figures 5(a) and 5(b)). The results indicate that Huaier aqueous extract decreases the secretion of DARC ligands by MCF-7 and MDA-MB-231 cells in vitro.

\section{Discussion}

Duffy antigen is an antigenic determinant of the Duffy blood group system that is first found on vivax for its entry into human red blood cells [18]. Human DARC can selectively bind to proinflammatory CC, angiogenic $\mathrm{ELR}^{+} \mathrm{CXC}$ (glutamic acid leucine-arginine+), and CXC chemokines 


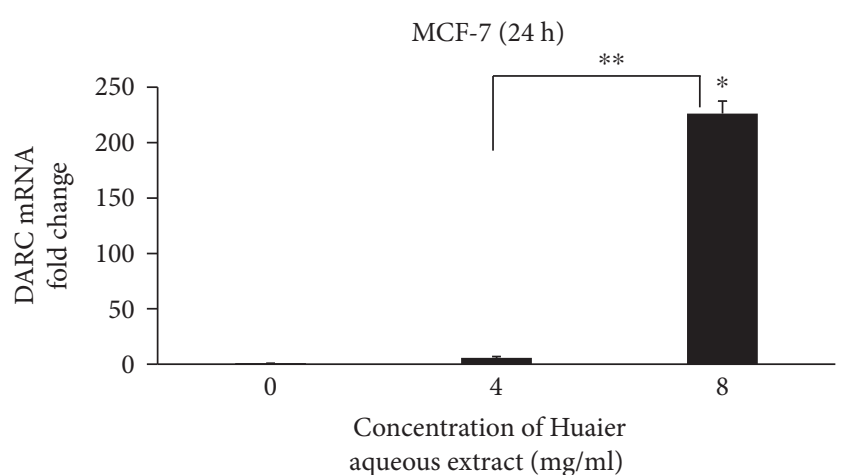

(a)

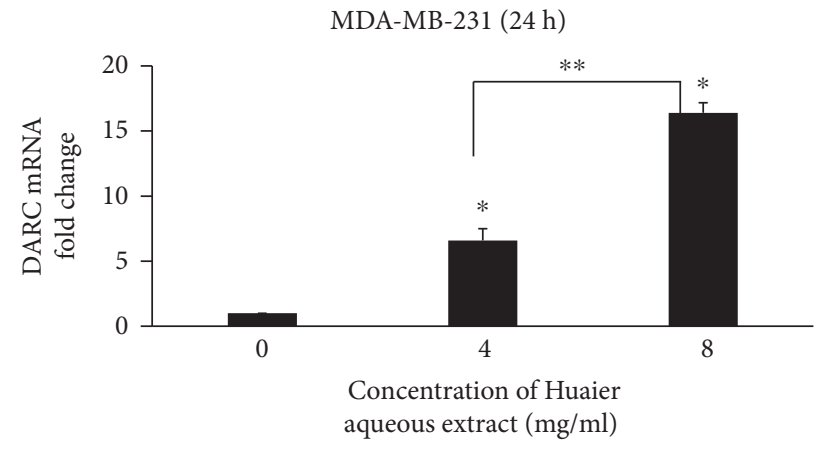

(c)

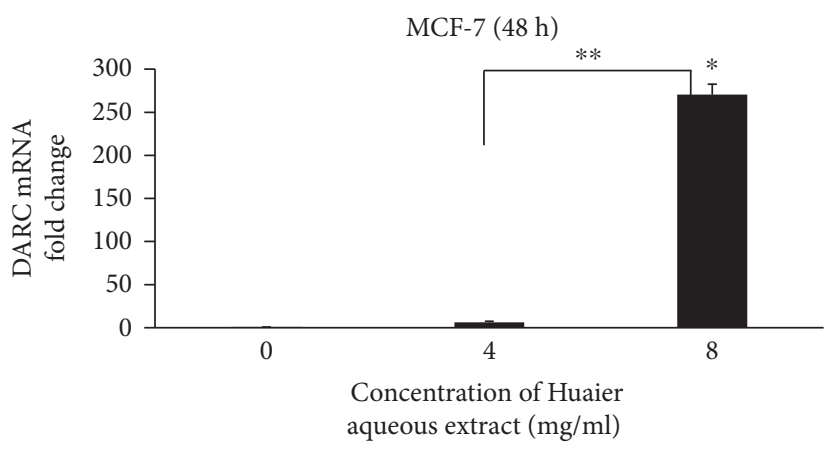

(b)

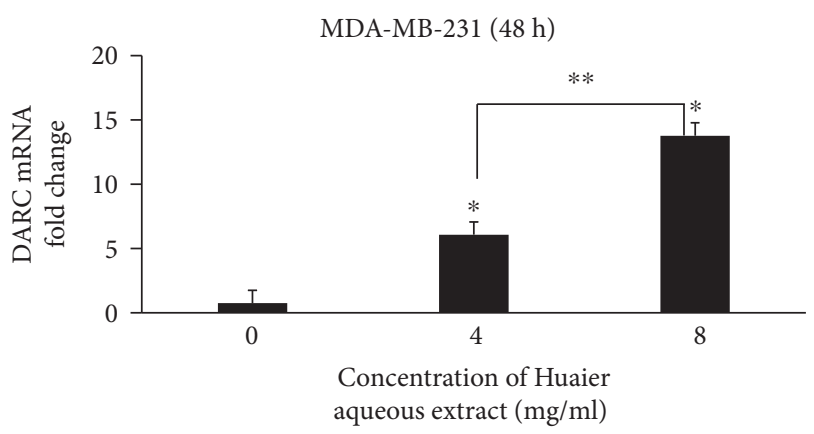

(d)

Figure 2: Effect of Huaier aqueous extract on DARC mRNA expression in (a, b) MCF-7 cells and (c, d) MDA-MB-231 cells after treatment with different concentrations ( 4 or $8 \mathrm{mg} / \mathrm{ml}$ ) of Huaier aqueous extract for 24 or $48 \mathrm{~h}$. Quantitative real-time polymerase chain reaction was used to measure mRNA expression. ${ }^{*} P<0.05$ compared with values at $0 \mathrm{mg} / \mathrm{ml}$. ${ }^{* *} P<0.05$ between $8 \mathrm{mg} / \mathrm{ml}$ and $4 \mathrm{mg} / \mathrm{ml}$ groups.

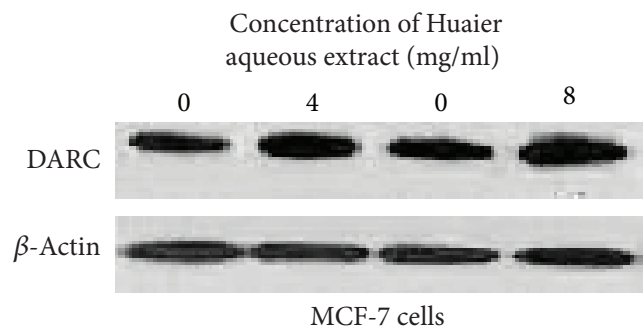

(a)

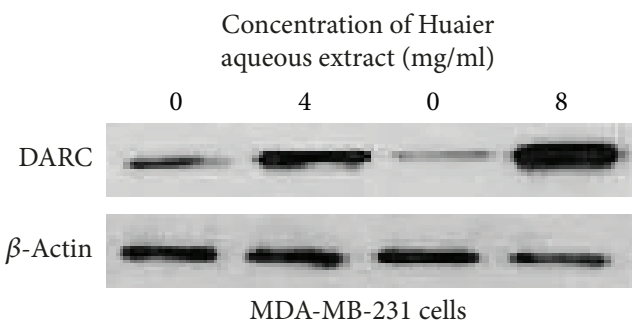

(b)
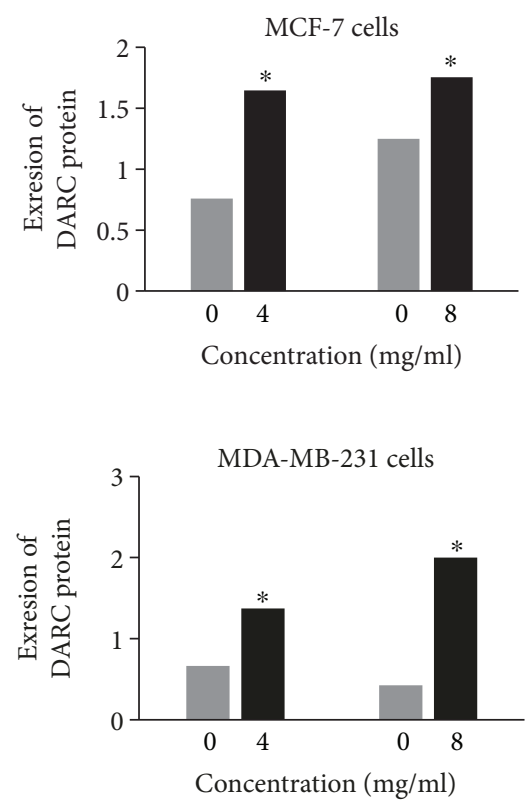

FIGURE 3: Effect of Huaier aqueous extract on DARC protein expression in (a) MCF-7 cells and (b) MDA-MB-231 cells after treatment with different concentrations ( 4 or $8 \mathrm{mg} / \mathrm{ml}$ ) of Huaier aqueous extract for $48 \mathrm{~h}$. Western blotting was used to measure protein expression. The histogram shows the grey level change in different conditions. ${ }^{*} P<0.05$ compared with $4 \mathrm{mg} / \mathrm{ml}$ group at the same time point. 


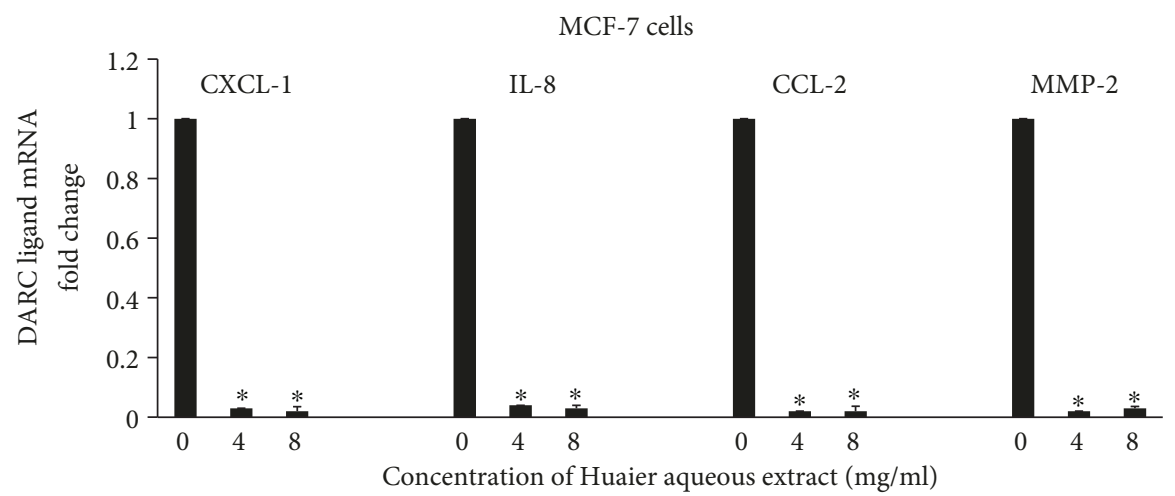

(a)

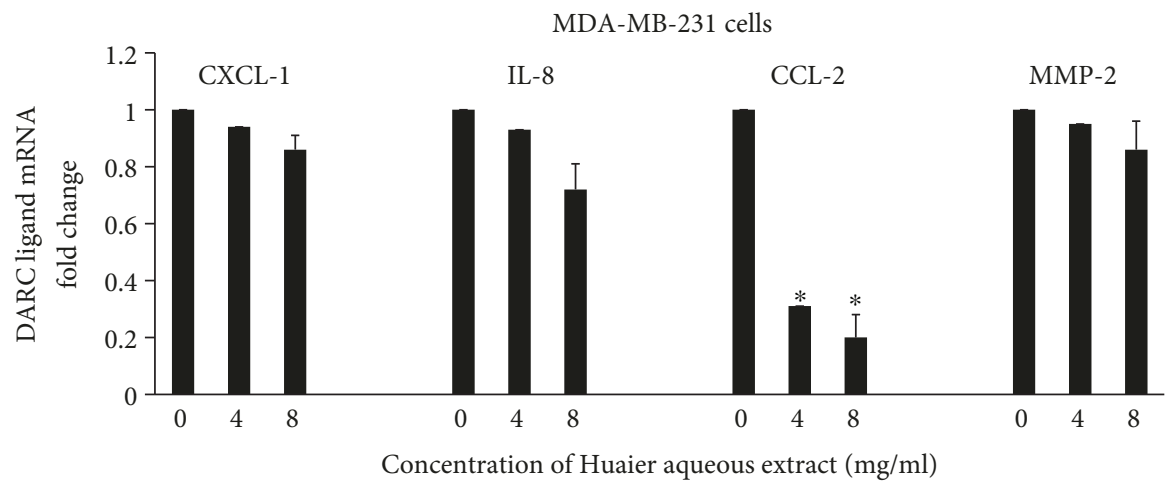

(b)

FIGURE 4: Effect of Huaier aqueous extract on the expression of DARC ligands. Expression of mRNA of CXCL-1, IL-8, CCL-2, and MMP-2 in (a) MCF-7 cells and (b) MDA-MB-231 cells treated by different concentrations ( 4 or $8 \mathrm{mg} / \mathrm{ml}$ ) of Huaier aqueous extract for $24 \mathrm{~h}$. Expression of mRNA was assessed by quantitative real-time polymerase chain reaction. ${ }^{*} P<0.05$ compared with values at $0 \mathrm{mg} / \mathrm{ml}$.

with high affinity. Although DARC is structurally similar to other chemokine receptors, it does not induce $\mathrm{G}$ proteincoupled signal transduction or $\mathrm{Ca}^{2+}$. Therefore, DARC is unable to couple to signal transduction pathways activated by typical chemokine receptors when artificially expressed in in vitro cellular systems $[19,20]$. DARC controls chemokine through different ways, including chemokine release into blood, posttranslational modifications of plasma chemokines, and DARC-independent removal mechanism $[21,22]$. Since DARC binds with angiogenic CXC chemokines, as well as some CC chemokines, by preventing the biological effects of these chemokines, DARC can induce tumor necrosis and antimetastatic effect [23].

It is shown that DARC is involved as a negative regulator in breast cancers, mainly by sequestration of angiogenic chemokines and subsequent inhibition of tumor neovascularity. DARC overexpression induces inhibition of tumorigenesis and/or metastasis through interfering with tumor angiogenesis in vivo [10]. DARC is found to bind angiogenic $\mathrm{ELR}^{+}$ CXC chemokines CXCL- 1 and IL- 8 and play a negative role in tumor progression through the control of angiogenesis by reducing angiogenic $\mathrm{ELR}^{+} \mathrm{CXC}$ chemokine secretion [24]. Another ligand, CCL-2, has been found to have the ability to accelerate tumor growth and metastasis of cancer cells upon binding with typical specific receptors. Overexpression of DARC in human breast cancer cells has been reported to downregulate CCL-2 levels and subsequently inhibit the proliferation and metastasis of breast cancer cells in vivo and in vitro [10]. MMP-2 plays a crucial role in the progression of breast cancer by degrading extracellular matrix (ECM) components [25]. MMP-2 is also an important ligand of DARC.

The absence of multiple atypical chemokine binders such as DARC, D6, and CCX-CKR, which is associated with higher VEGF and MMP-9 expression, predicts the presence and extent of ALN metastasis in breast cancer [26]. Moreover, DARC isoforms in the tumor microenvironment could reduce the levels of promalignant chemokines in different degrees, have differential effects on tumor growth and vascularization, and contribute to differential potential of metastasis [4]. In addition, the concentration of DARC in serum of patients is significantly correlated with the relapse risk of patients [27]. However, the different effects of DARC between primary and metastatic breast cancers have not been well known.

To investigate the expression of DARC in primary and metastatic breast cancer, 30 cases with recurrence and metastasis are enrolled. We have detected the expression of DARC in the patients using immunohistochemical staining. Our findings demonstrate that DARC is reduced at different stages of breast cancer.

There are many reasons for the different expressions of DARC in primary and metastatic breast cancer, including tumor heterogeneity, false positive or false negative reactions, 


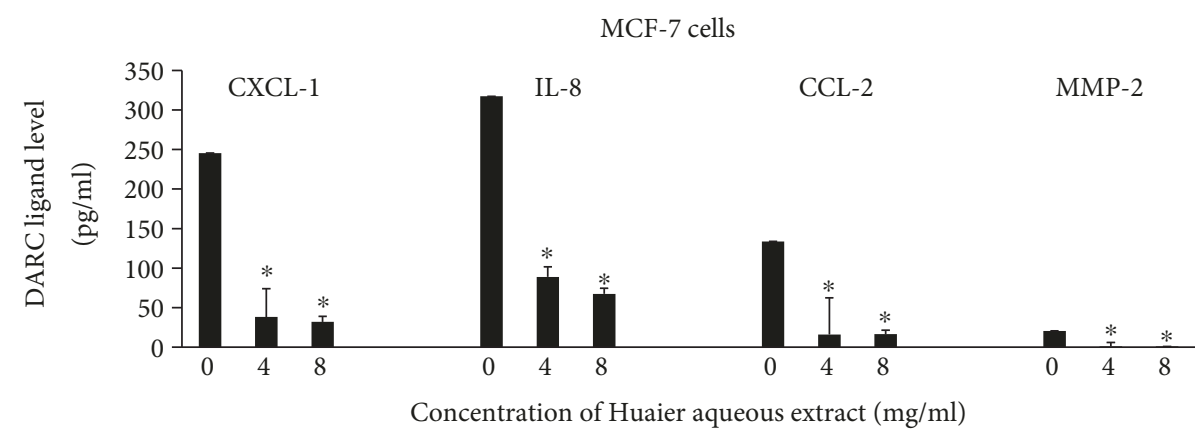

(a)

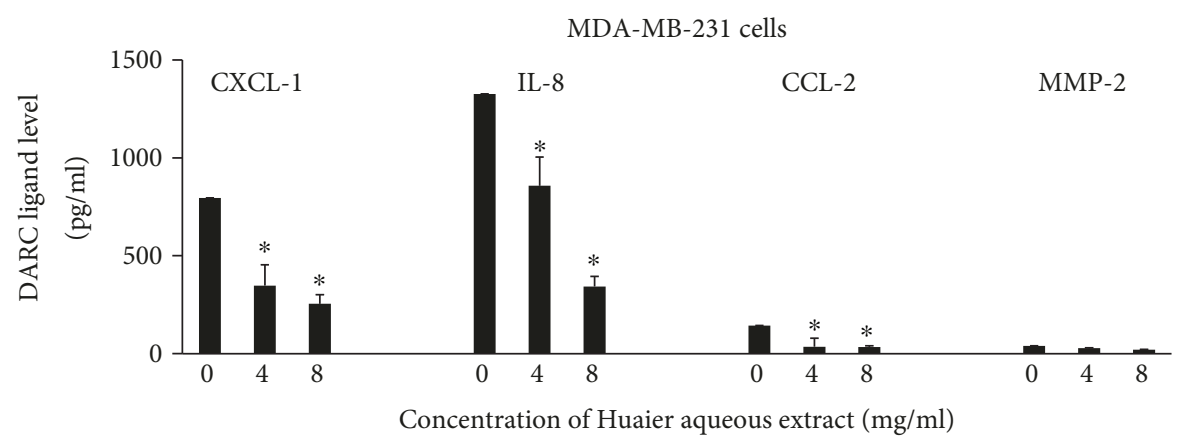

(b)

FIGURE 5: Effect of Huaier aqueous extract on the secretion of DARC ligands. The levels of CXCL-1, IL-8, CCL-2, and MMP-2 in conditioned medium of (a) MCF-7 cells and (b) MDA-MB-231 cells after the treatment of different concentrations (4 or $8 \mathrm{mg} / \mathrm{ml})$ of Huaier aqueous extract for $48 \mathrm{~h}$. The concentrations of secreted proteins were evaluated by ELISA. ${ }^{*} P<0.05$ compared with values at $0 \mathrm{mg} / \mathrm{ml}$.

and genetic drift or clonal selection [28]. In the present study, we also find changes of ER, PR, and HER2 expression in primary and metastatic tissues. However, there is no statistically significant difference (data was not shown). This result is in accordance with a meta-analysis reported in 2015 [29]. The reduced expression of DARC in metastatic or recurrent tissues may prompt an important role in breast cancer progression and have a relationship with tumor recurrence and metastasis. Since DARC expression is reduced, the related angiogenic chemokines may be overexpressed. Breast cancer cells may become active and metastasize to distant positions. Therefore, any drug that can promote DARC expression in breast cancer cells may reduce cancer metastasis.

In the treatment for cancers, TCM has become more and more popular for its convenient intaking, inexpensiveness, and less harm to normal cells. Huaier is a type of fungus that has been used in TCM for many years. The drug, which is already approved by the Chinese Food and Drug Administration, has been used in many kinds of cancer patients [30]. However, the effect of Huaier aqueous extract on DARC and its ligands has not been investigated.

Our experiment shows that Huaier aqueous extract not only improves the expression of DARC in vitro but also reduces the expression of its ligands such as CCL-2, IL-8, MMP-2, and CXCL-1, especially in MCF-7 cells. However, DARC is confirmed to be a powerful chemokine controller in posttranslational stages rather than in translational stages. Therefore, DARC does not affect chemokine mRNA expression commonly. Although the secretion of CCL-2, IL-8, MMP-2, and CXCL-1 is reduced in vitro, it is not definite that Huaier aqueous extract can reduce ligand secretion by promoting the expression of DARC. Since Huaier aqueous extract can cause apoptosis of cells, this may affect protein secretion.

In conclusion, our study demonstrates that expression of DARC is reduced in metastatic breast cancer tissues, and Huaier aqueous extract affects the expression of DARC and its ligands. However, the present study only included a limited number of patients, and more samples are needed for further investigations. Moreover, we will carry out in vivo experiments in the future.

\section{Data Availability}

The data used to support the findings of this study are available from the corresponding author upon request.

\section{Conflicts of Interest}

All authors declare no financial competing interests.

\section{Acknowledgments}

This study was supported by the grant from the National Natural Science Foundation of China (no. 81573651).

\section{References}

[1] L. Fan, K. Strasser-Weippl, J. J. Li et al., "Breast cancer in China," The Lancet Oncology, vol. 15, no. 7, pp. e279-e289, 2014. 
[2] T. Foukakis, T. Fornander, T. Lekberg, H. Hellborg, J. Adolfsson, and J. Bergh, "Age-specific trends of survival in metastatic breast cancer: 26 years longitudinal data from a population-based cancer registry in Stockholm, Sweden," Breast Cancer Research and Treatment, vol. 130, no. 2, pp. 553-560, 2011.

[3] t V. Van, J. Laura, H. Dai et al., SEER Stat Fact Sheets: Breast Cancer, Nature, 2014.

[4] C. Yang, K. D. Yu, W. H. Xu et al., "Effect of genetic variants in two chemokine decoy receptor genes, DARC and CCBP2, on metastatic potential of breast cancer," PLoS One, vol. 8, no. 11, article e78901, 2013.

[5] A. Rot, "Contribution of Duffy antigen to chemokine function," Cytokine \& Growth Factor Reviews, vol. 16, no. 6, pp. 687-694, 2005.

[6] F. R. M. Latini, A. U. Bastos, C. P. Arnoni et al., "DARC (Duffy) and BCAM (Lutheran) reduced expression in thyroid cancer," Blood Cells, Molecules, and Diseases, vol. 50, no. 3, pp. 161-165, 2013.

[7] T. Hou, D. Liang, L. Xu, X. Huang, Y. Huang, and Y. Zhang, "Atypical chemokine receptors predict lymph node metastasis and prognosis in patients with cervical squamous cell cancer," Gynecologic Oncology, vol. 130, no. 1, pp. 181-187, 2013.

[8] B. Nemesure, S. Y. Wu, A. Hennis, and M. C. Leske, "Distribution of Duffy antigen receptor for chemokines (DARC) and risk of prostate cancer in Barbados, West Indies," Journal of Immigrant and Minority Health, vol. 17, no. 3, pp. 679-683, 2015.

[9] S. Zhou, M. Liu, Y. Hu et al., "Expression of Duffy antigen receptor for chemokines (DARC) is down-regulated in colorectal cancer," Journal of Receptors and Signal Transduction, vol. 35, no. 5, pp. 462-467, 2015.

[10] J. Wang, Z. L. Ou, Y. F. Hou et al., "Enhanced expression of Duffy antigen receptor for chemokines by breast cancer cells attenuates growth and metastasis potential," Oncogene, vol. 25, no. 54, pp. 7201-7211, 2006.

[11] N. Zhang, X. Kong, S. Yan, C. Yuan, and Q. Yang, "Huaier aqueous extract inhibits proliferation of breast cancer cells by inducing apoptosis," Cancer Science, vol. 101, no. 11, pp. 2375-2383, 2010.

[12] L. Yan, X. Liu, A. Yin, Y. Wei, Q. Yang, and B. Kong, "Huaier aqueous extract inhibits cervical cancer cell proliferation via JNK/p38 pathway," International Journal of Oncology, vol. 47, no. 3, pp. 1054-1060, 2015.

[13] Z. Zhu, Z. Sun, Z. Wang, P. Guo, X. Zheng, and H. Xu, "Prognostic impact of atypical chemokine receptor expression in patients with gastric cancer," Journal of Surgical Research, vol. 183, no. 1, pp. 177-183, 2013.

[14] F. Zhang, Z. Zhang, and Z. Liu, "Effects of Huaier aqueous extract on proliferation and apoptosis in the melanoma cell line A875," Acta Histochemica, vol. 115, no. 7, pp. 705-711, 2013.

[15] X. Song, Y. Li, H. Zhang, and Q. Yang, "The anticancer effect of Huaier (review)," Oncology Reports, vol. 34, no. 1, pp. 12-21, 2015.

[16] T. Zhang, K. Wang, J. Zhang et al., "Huaier aqueous extract inhibits colorectal cancer stem cell growth partially via downregulation of the Wnt/ $\beta$-catenin pathway," Oncology Letters, vol. 5, no. 4, pp. 1171-1176, 2013.

[17] A. Goldhirsch, E. P. Winer, A. S. Coates et al., "Personalizing the treatment of women with early breast cancer: highlights of the St Gallen International Expert Consensus on the Primary Therapy of Early Breast Cancer 2013," Annals of Oncology, vol. 24, no. 9, pp. 2206-2223, 2013.

[18] X. H. Liu, T. J. Hadley, L. Xu, S. C. Peiper, and P. E. Ray, "Upregulation of Duffy antigen receptor expression in children with renal disease," Kidney International, vol. 55, no. 4, pp. 1491-1500, 1999.

[19] Y. Chen, N. Liao, F. Lu, H. Peng, and J. Gao, "The role of Duffy antigen receptor for chemokines in keloids," Gene, vol. 570, no. 1, pp. 44-49, 2015.

[20] K. Neote, W. Darbonne, J. Ogez, R. Horuk, and T. J. Schall, "Identification of a promiscuous inflammatory peptide receptor on the surface of red blood cells," Journal of Biological Chemistry, vol. 268, no. 17, pp. 12247-12249, 1993.

[21] S. L. Harrison, P. Vavken, and M. M. Murray, "Erythrocytes inhibit ligament fibroblast proliferation in a collagen scaffold," Journal of Orthopaedic Research, vol. 29, no. 9, pp. 1361-1366, 2011.

[22] P. Bao, A. Kodra, M. Tomic-Canic, M. S. Golinko, H. P. Ehrlich, and H. Brem, "The role of vascular endothelial growth factor in wound healing," Journal of Surgical Research, vol. 153, no. 2, pp. 347-358, 2009.

[23] S. Bandyopadhyay, R. Zhan, A. Chaudhuri et al., "Interaction of KAI1 on tumor cells with DARC on vascular endothelium leads to metastasis suppression," Nature Medicine, vol. 12, no. 8, pp. 933-938, 2006.

[24] A. L. Chew, W. Y. Tan, and B. Y. Khoo, "Potential combinatorial effects of recombinant atypical chemokine receptors in breast cancer cell invasion: a research perspective," Biomedical Reports, vol. 1, no. 2, pp. 185-192, 2013.

[25] J. Van Horssen, C. M. P. Vos, L. Admiraal et al., "Matrix metalloproteinase-19 is highly expressed in active multiple sclerosis lesions," Neuropathology and Applied Neurobiology, vol. 32, no. 6, pp. 585-593, 2006.

[26] X. H. Zeng, Z. L. Ou, K. D. Yu et al., “Absence of multiple atypical chemokine binders (ACBs) and the presence of VEGF and MMP-9 predict axillary lymph node metastasis in early breast carcinomas," Medical Oncology, vol. 31, no. 9, p. 145, 2014.

[27] J. Wang, Q. He, Y. G. Shao, and M. Ji, "Chemokines fluctuate in the progression of primary breast cancer," European Review for Medical and Pharmacological Sciences, vol. 17, no. 5, pp. 596-608, 2013.

[28] E. Curtit, V. Nerich, L. Mansi et al., "Discordances in estrogen receptor status, progesterone receptor status, and HER2 status between primary breast cancer and metastasis," The Oncologist, vol. 18, no. 6, pp. 667-674, 2013.

[29] S. Rossi, M. Basso, A. Strippoli et al., "Hormone receptor status and HER2 expression in primary breast cancer compared with synchronous axillary metastases or recurrent metastatic disease," Clinical Breast Cancer, vol. 15, no. 5, pp. 307-312, 2015.

[30] X. Yan, T. Lyu, N. Jia, Y. Yu, K. Hua, and W. Feng, "Huaier aqueous extract inhibits ovarian cancer cell motility via the AKT/GSK3 $\beta / \beta$-catenin pathway," PLoS One, vol. 8, no. 5, article e63731, 2013. 


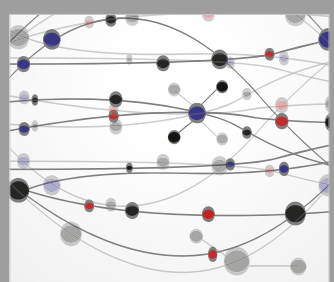

The Scientific World Journal
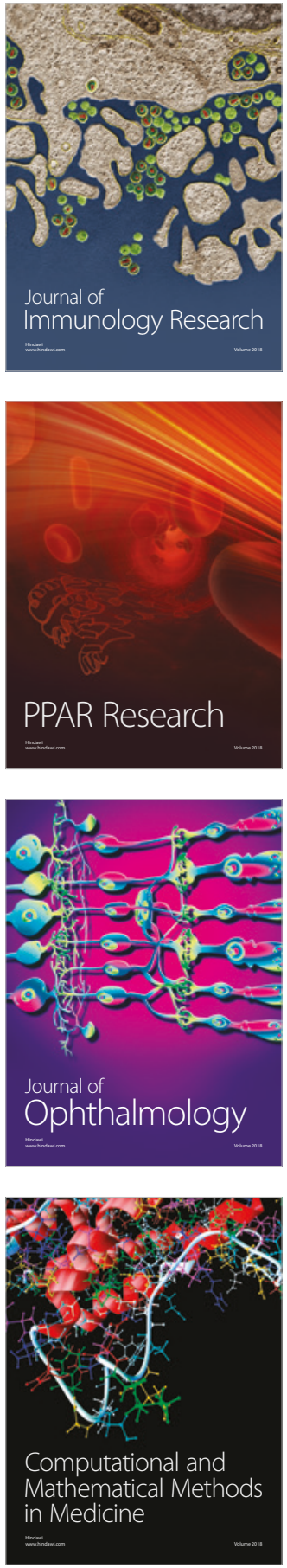

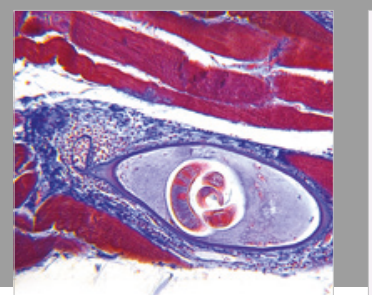

Gastroenterology Research and Practice

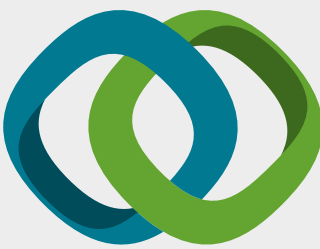

\section{Hindawi}

Submit your manuscripts at

www.hindawi.com
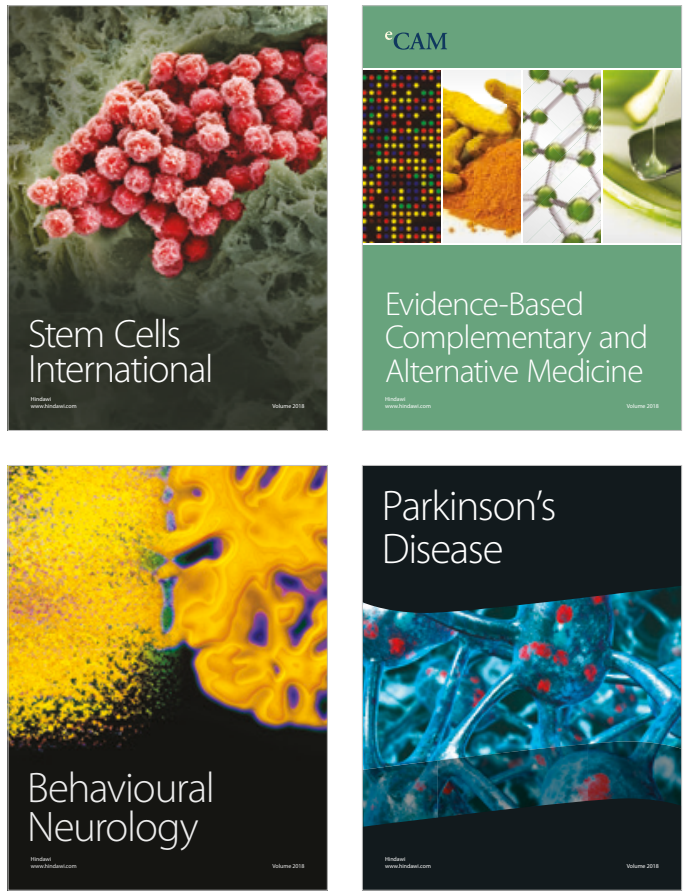

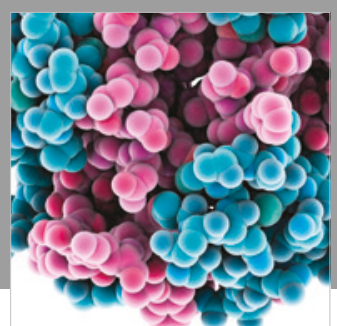

ournal of

Diabetes Research

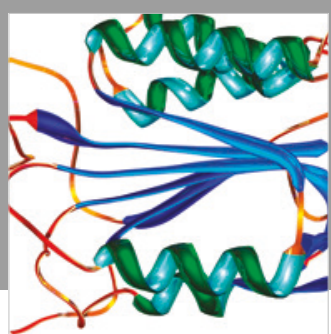

Disease Markers
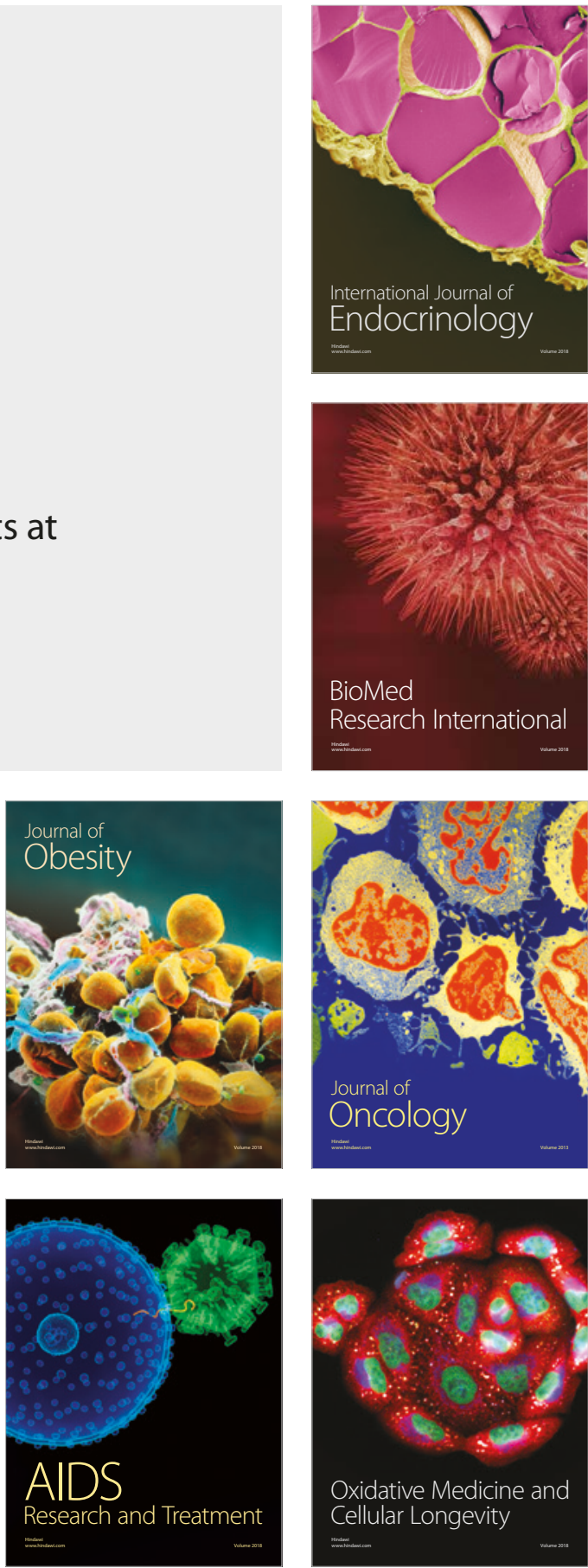